\title{
Guidelines for Reporting Parabolic Trough Solar Electric System Performance
}

\section{RECEIVED}

JUL $0^{3} 1997$

OSTI

Henry W. Price

National Renewable Energy Laboratory

Prepared for the International Energy Agency SolarPACES, "Guidelines for Reporting on Solar Concentrating Systems"
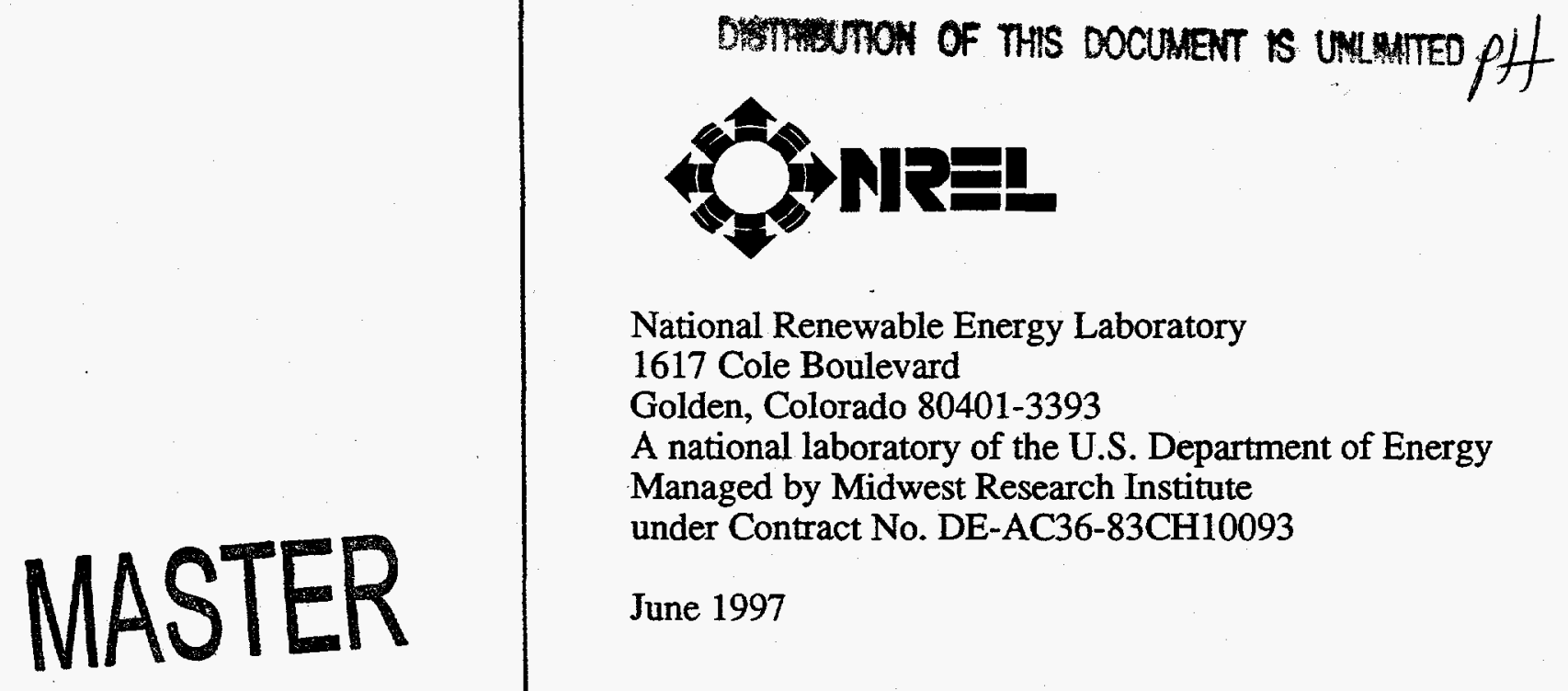

National Renewable Energy Laboratory 1617 Cole Boulevard Golden, Colorado 80401-3393

A national laboratory of the U.S. Department of Energy Managed by Midwest Research Institute under Contract No. DE-AC36-83CH10093

June 1997 


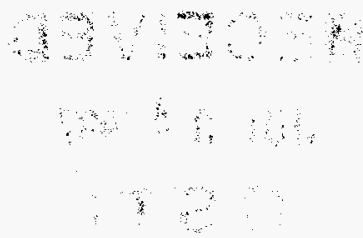

\section{NOTICE}

This report was prepared as an account of work sponsored by an agency of the United States government. Neither the United States government nor any agency thereof, nor any of their employees, makes any warranty, express or implied, or assumes any legal liability or responsibility for the accuracy, completeness, or usefulness of any information, apparatus, product, or process disclosed, or represents that its use would not infringe privately owned rights. Reference herein to any specific commercial product, process, or service by trade name, trademark, manufacturer, or otherwise does not necessarily constitute or imply its endorsement, recommendation, or favoring by the United States govemment or any agency thereof. The views and opinions of authors expressed herein do not necessarily state or reflect those of the United States government or any agency thereof.

Available to DOE and DOE contractors from:

Office of Scientific and Technical Information (OSTI)

P.O. Box 62

Oak Ridge, TN 37831

Prices available by calling (423) 576-8401

Available to the public from:

National Technical Information Service (NTIS)

U.S. Department of Commerce

5285 Port Royal Road

Springfield, VA 22161

(703) $487-4650$ 


\section{DISCLAMMER}

Portions of this document may be illegible in electronic image produets. Images are produced from the best available original docoment. 


\title{
GUDELINES FOR REPORTING PARABOLIC TROUGH SOLAR ELECTRIC SYSTEM PERFORMANCE
}

\author{
Henry W. Price \\ Sun $\bullet$ Lab \\ National Renewable Energy Laboratory \\ Golden, Colorado 80401-3393 (USA) \\ Phone: (303) 384-7437, Fax: (303) 384-7495 \\ E-mail: henry_price@nrel.gov
}

\section{INTRODUCTION}

The purpose of this activity is to develop a generic methodology which can be used to track and compare the performance of parabolic trough power plants. The approach needs to be general enough to work for all existing and future parabolic trough plant designs, provide meaningful comparisons of year to year performance, and allow for comparisons between dissimilar plant designs. The approach presented here builds on the earlier work for trough [1] and dish systems [2], and uses the net anmual system efficiency as the primary metric for evaluating the performance of parabolic trough power plants. However, given the complex nature of large parabolic trough plants, the net annual system efficiency by itself does not adequately characterize the performance of the plant. The approach taken here is to define a number of additional performance metrics which enable a more comprehensive understanding of overall plant performance.

\section{BACKGROUND}

Parabolic trough technology is currently the most commercialized solar thermal electric technology. This is primarily due to the nine SEGS (Solar Electric Generating System) plants developed Luz International Limited between 1984 and 1990, representing 354 MWe of installed electric generating capacity. Although Luz went into bankruptcy in 1991 while attempting to build its tenth plant, all nine of the earlier plants continue to operate today.

All of the SEGS plants have large fields of parabolic trough solar collectors and conventional Rankine cycle steam power blocks. The parabolic trough collectors track the sun such that the direct radiation from the sun is focused on the receiver tube. A high temperature heat transfer fluid (HTF) is heated as it is circulated through the receiver, and is returned to the power block. The HTF then passes through heat exchangers to generate steam which is sent to a turbine/generator to produce electricity. Although all of the existing SEGS plants are generally similar, there are some differences between the plants. These differences usually deal with the particular design of the power blocks and how the plant is hybridized with fossil energy. These factors usually dictate the required operating temperature of the solar plant as well.

Future parabolic trough power plants are likely to have even more significant design differences. In an effort to reduce the cost of future plants, designers have proposed integrating the parabolic trough solar plant with gas-turbine combined-cycle power plants or using direct steam parabolic trough collector technology. Thus, any guidelines developed for evaluating the performance of parabolic trough power plants need to be general enough to apply to all existing as well as any future parabolic trough plants. 


\title{
3. TROUGH PERFORMANCE EVALUATION
}

A number of metrics have been used for evaluating the performance of parabolic trough plants in the past. The operators of the SEGS facilities typically report net electric generation and on-peak capacity factors, and on occasion have shown charts of daily solar output as a function of solar radiation input [3]. Other studies have looked at the thermal performance of the parabolic trough collectors $[4,5]$ or compared the performance of the plants to predicted performance simulation codes $[6,7]$. One study, by Sandia National Laboratories [1], developed a methodology and calculated the net annual electric efficiency of the SEGS III-VII hybrid trough plants for 1988 through 1993. The methodology developed in that study provides the basis for the performance reporting standards developed here.

\section{Net System Efficiency}

As with dish/Stirling systems, the key performance parameter of interest for parabolic trough plants is the net system efficiency. Using the net system efficiency allows the performance of parabolic trough plants to be compared to other solar electric technologies. Theoretically the net system efficiency can be evaluated on an instantaneous basis or integrated over time. For small systems such at dish/Stirling technologies, it is possible to evaluate the net system efficiency verses solar input on an instantaneous basis. However, for large trough plants this is generally not possible because of their size and since the troughs track the sun on a single axis. These two effects result in extended time for the overall system to respond to transients and a constantly varying solar input due to the changing solar incidence angle. As a result, calculating efficiencies on an instantaneous basis can be misleading and result in erroneous conclusions.

The net system efficiency can be evaluated on a daily basis, but again because of single axis tracking, comparisons between different times of the year or for plants at different latitudes can be confusing. In addition, plants with thermal storage can shift significant portions of generation from one day to the next. For these reasons, the approach suggested in these guidelines is to use the net anmual system efficiency as the primary performance metric for evaluating parabolic trough plants.

\section{Additional Performance Metrics}

Analysis of large parabolic trough power plants is complicated by the huge size of the solar field, the complex interaction between the solar field and power block, and the fact that all existing plants are hybrid plants that use both solar and fossil energy input. Although the net system efficiency is a useful metric, additional information is necessary to gain a complete understanding of plant performance. Additional metrics on the level of solar radiation, solar plant status, solar field and power plant availability, parasitic loads, and hybrid solar/fossil operation are required to provide a comprehensive understanding of overall plant performance. Table 1 lists the categories of standardized performance metrics which have been developed for the evaluation of parabolic trough power plants. The specific performance metrics for each of these categories is developed in the next section.

\section{Table 1. Standardized Performance Metric Categories}

\author{
Plant Design Characteristics \\ Solar Input \\ Collector Field Status \\ Plant Availability \\ Fossil Fuel Consumption \\ Electric Generation and Consumption \\ Plant Capacity factors and Solar Fraction \\ Net system efficiency
}




\section{STANDARDIZED PERFORMANCE METRICS}

Although, much can be learned from looking at instantaneous, hourly, daily, or monthly performance data, these guidelines recommend that only annual summary data is to be reported. Annual data gives a better summary of how the plant performs over extended periods of time and allows easier, although less rigorous, comparisons to the expected performance of the plant. In addition, it reduces the amount of data that must be reported and analyzed.

\section{Plant Design Characteristics}

A general knowledge of the plant design is essential for understanding the performance of the plant. Plant design characteristics which should be reported include a general description of plant configuration and modes of operation. General information about the plant including location, and first year of operation. Solar field parameters to be reported include: solar field size (aperture area as defined by ref. [2]), the collector technology used, the heat transfer fluid used, the design operating temperature, and the amount of thermal storage. Power block characteristics to be reported include: design net electric capacity, description of how the plant is hybridized (if relevant), solar and fossil design point operating efficiencies, and a description of typical operational modes. Ideally, process flow diagrams should be included for each plant reported on.

\section{Solar Input}

For concentrating collectors like parabolic troughs, the direct normal insolation (DNI) is the solar parameter of interest. DNI is the beam component of solar radiation in a plane normal to the direction of the sun $\left(\mathrm{G}_{\mathrm{bn}}\right)$. DNI is normally measured with an Epply normal incidence pyroheliometer (NIP) or similar instrument. To get accurate readings, it is important that the instrument be sited with an unobstructed view of the sun during the full day for all seasons of the year. It is important to make sure the instrument is correctly aligned so that it tracks the sun accurately through out the entire day. Daily checks of the alignment and cleaning of the lens aperture are suggested. It is also important that the instrument be recalibrated every year or two since the sensitivity of the instrument degrades with time. Periodic recalibration of the transmitters between the NIP an the data acquisition system should be performed at least once a year as well. The DNI data should be integrated to get daily totals $\left(\mathrm{H}_{\mathrm{bn}}\right)$.

$$
H_{b n}=\sum_{0}^{24} G_{b n}
$$

\section{Collector Field Status}

When the performance of a single dish/Stirling concentrator is evaluated it is generally possible to quantify mirror reflectivity, receiver heat losses, concentrator alignment, and engine performance characteristics. With large parabolic trough plants, such as the SEGS plants, it is generally more difficult to accurately characterize the condition of the solar field collectors. By way of example, the 80 MWe SEGS IX plant has: 888 Individually tracking collectors, 148 parallel HTF flow paths, 21,312 receiver tubes (over $85 \mathrm{~km}$ of pipe with a selective coating), and 198,912 individual mirror elements (483,960 m2 of aperture). The task of accurately characterizing the mirror reflectivity, receiver absorptance, concentrator alignment, and heat losses of a system this large is difficult at best. To account for this, a number of simple statistics are proposed which provide general indications of plant condition without requiring extensive measurement of collector efficiency parameters. 
Collector Availability: In plants with large fields of independently tracking solar collectors, it is desirable to calculate collector availability, which is the fraction of the collectors capable of tracking the sun. In general the simplest approach for obtaining collector availability is to use the actual fraction of collectors tracking which is usually available on the solar field supervisory control computer. Typically, tracking figures are recorded hourly and averaged to obtain a daily value. The daily values are then used to obtain monthly and annual average tracking figures. Usually tracking data during transient periods, such as during start-up, or during cloudy periods are not include in the averages, since these do not reflect the true capability of the field.

Parabolic trough plants with out thermal storage usually must defocus portions of the solar field during portions of Spring and Summer days because the thermal collection capability of the solar field is greater than the power block's capability to use the thermal energy. As a result, portions of the field are defocused, commonly refered to as dumped, which reduces the fraction of the field tracking. Thus, years with higher solar radiation levels can actually cause lower average solar field tracking values. One way to compensate for this is to also report the maximum percentage of collectors available to track. This figure is somewhat more subjective and could either be defined as the maximum number of collectors tracking on any day or be calculated by determining the number of collectors which are out-of-service for maintenance or not otherwise operational.

Receiver Tube Status: The condition of the parabolic trough receiver can have a major impact on collector performance. All of the Luz collectors use a stainless steel receiver tube with a selective surface, encased in an evacuated glass annulus. These receiver tubes have proven to be very efficient with low heat losses at the elevated operating temperatures. However, a number of the SEGS plants have experienced a significant number of receiver tube failures including loss of vacuum, breakage of the glass annulus, and selective coating defects. Experimental testing at Sandia National Laboratories in Albuquerque, New Mexico [5] has shown that heat losses double when the vacuum is lost, and the heat losses can be five times as much, depending on wind velocity, if the glass annulus is completely removed. Defects in the selective coating can dramatically reduce the energy absorbed by the receiver. To account for actual field receiver tube status, the percent of receiver tubes which have lost vacuum, broken the glass annulus, or selective coating defects should be reported.

Mirror Module Status: The Luz collectors utilize a 4mm.thick, second surface, silvered glass parabolic reflector. Mirror failures, although generally a small percentage of the total number installed, can add up over time. Since the mirrors are essential for the collection of energy, the average annual percentage of mirror area missing and area with degraded reflective surface should be reported.

Mirror Cleanliness: The experience at the SEGS plants have proven the need for periodically cleaning the surface of the mirrors. Routine mirror washing can have the single largest impact on annual plant performance of any maintenance activity. As a result, some indication of mirror cleanliness is important for understanding actual plant performance. Although, some form of mirror reflectivity measurement would seem to be the best indicator of field cleanliness, it is difficult to get an accurate measurement which characterizes the total field condition. In addition, some form of extrapolation would need to be used during periods when measurements are not taken. To simplify the problem, reporting of average mirror wash frequency is suggested.

$$
\text { Wash Cycle }=\left(\frac{52 \times \text { collectors in field }}{\text { total number of collectors washed during the year }}\right) \text { in weeks }
$$

The mirror wash cycle indicates the average number of weeks between mirror washing. Heavy rains or snowfall which provide good cleaning should be counted as a wash for the entire field. Consecutive rain washes should not be included unless they are spaced at least 1 or 2 weeks apart. 


\section{Plant Availability}

It is important that the power block be availabile to convert solar thermal energy into electricity whenever the sun is shining. Thus, some form of indication of power plant availability is desirable. Conventional power plants utilize the North American Electric Reliability Council's Generating Availability Data System (NERC GADS) [8] for reporting power plant availability and the causes of non-availability. Unfortunately, this methodology does not make sense to directly apply to solar power facilities. Until an appropriate system is developed for solar power plants, a simplified approach is used to calculate a solar plant availability. This approach calculates the number of hours that the plant should be available to operate in solar operation, and tracks the number of hours that non-solar collector equipment or events prevent the solar field from operating when it would otherwise be operating.

Equation 3 defines the number of hours that the solar plant could operate given clear skies and that the power block must be available to achieve $100 \%$ availability.

$$
S H=\sum_{1}^{365}\left(t_{\text {STOW }}-t_{\text {DEPLOT }}\right)
$$

SH

solar hours: is the total number of hours during the year that the solar field could track the sun if the sky were clear

$t_{D E P L O Y}$ deploy time: is the time the solar field could begin tracking based on the sun 's elevation angle above the eastern horizon

$t_{\text {STOW }}$ stow time: is the time the solar field can no longer track based on the sun's elevation angle above the western horizon.

Equation 4 defines the categories of non-availability for hours of forced and scheduled plant outages.

$$
\mathrm{X}_{\mathrm{TOTAL}}=\mathrm{X}_{\mathrm{SF}}+\mathrm{X}_{\mathrm{HTF}}+\mathrm{X}_{\mathrm{HX}}+\mathrm{X}_{\mathrm{PB}}+\mathrm{X}_{\mathrm{OP}}+\mathrm{X}_{\mathrm{SM}}+\mathrm{X}_{\mathrm{WND}}
$$

Where:

$X_{\text {TOTAL }}$ total hours when the solar field is stowed when it would otherwise be operating

$\mathrm{X}_{\mathrm{SF}} \quad$ solar field: outage hours due to solar field control computers and communications

$X_{\mathrm{HTF}} \quad \mathrm{HTF}$ system: outage hours due to HTF pumps, piping, vessels, and thermal storage

$\mathrm{X}_{\mathrm{FX}} \quad$ heat exchangers: outage hours due to solar/steam heat exchangers

$\mathrm{X}_{\mathrm{PB}} \quad$ power block: outage hours on turbine/generator, feedwater/condensate, cooling tower

$\mathrm{X}_{\mathrm{OP}} \quad$ operational: outage hours resulting from operator error or scheduling

$\mathrm{X}_{\mathrm{SM}} \quad$ scheduled: annual maintenance and maintenance planned months in advance

$X_{\text {WIND }}$ wind: hours when the solar field is stowed for high wind conditions

Plant availability $\left(\phi_{\text {PLANT }}\right)$ is then defined in equation 5 as:

$$
\phi_{\text {PLANT }}=\frac{S H-\mathrm{X}_{\text {TOTAL }}}{S H}
$$

Note that solar hours includes cloudy periods. Thus the plant is considered available even if it does not operate because of clouds as long as the power plant is otherwise able to operate. Plant outages must be recorded during both sunny and cloudy periods. The exception to this is if maintenance activities are being performed during cloudy periods and the plant could be returned to service as soon as the clouds clear up. 
Cloudy Days: Cloudy weather is not included in the forced and scheduled outage data because it is accounted for in the annual direct normal insolation data. However, additional information on the number of days the plant does not operate or operates at significantly reduced levels because of clouds can be an important consideration for many potential sites. It is suggested that the number of days when no solar electric generation occurs and when less that $50 \%$ of the expected daily generation occurs, as a result of clouds, be reported. Note that the expected clear day electric production of a trough plant varies significantly during the year. The approach suggested for identifying days with $50 \%$ or greater reduction in generation is to use $50 \%$ of the best solar day during the month as the criteria, and making sure that the reduced performance on any counted day is due to clouds.

\section{Fossil Fuel Consumption}

Fossil fuels can be used for a number of purposes at parabolic trough power plants. These include superheating of solar generated steam, generating steam for electric generation when solar energy is not available, freeze protection of HTF, steam blanketing of the power block equipment at night, and other balance of plant functions. In general, it is important to be able to split the fossil fuel usage into categories by use. Equation 3 shows the breakdown of fossil fuel uses into its potential uses. Note that $\mathrm{Q}_{\mathrm{AuX}, \mathrm{GAS}}$ refers to auxiliary thermal uses like HTF freeze protection and stean blanketing, where as, $Q_{B O P, G A S}$ refers to non-thermal uses such as inert gas blanketing. In most cases, different pieces of equipment are used for each function. In cases where the same piece of equipment is used for multiple purposes, careful operator logs must be kept to allocate the gas usage to the proper category. In SEGS VIII \& IX the same auxiliary heaters are used for backup electric generation and for HTF freeze protection. In this case, operators are able to split the gas use appropriately because freeze protection usually occurs at night or early morning when the plant is not typically operated for power generation.

$$
Q_{\text {TOT }, G A S}=Q_{S H, G A S}+Q_{\text {ELEC }, G A S}+Q_{A U X, G A S}+Q_{B O P, G A S}
$$

Where:

$$
\begin{aligned}
& Q_{T O T, G A S} \text { is the total fossil fuel used by the plant for all purposes. } \\
& Q_{I S H, G A S} \quad \begin{array}{l}
\text { is the fossil fuel used by an independent superheater to superheat solar generated } \\
\text { steam. }
\end{array} \\
& Q_{E L E C, G A S} \text { is the fossil fuel used by an fossil fired steam boiler or an auxiliary oil heater to } \\
& \text { generate superheated steam for electric generation. } \\
& Q_{A U X, G A S} \quad \begin{array}{l}
\text { is the fossil fuel used by an fossil fired auxiliary oil heater when it is used to heat } \\
\text { the HTF for non-electric generation purposes such as HTF freeze protection or to } \\
\text { generate steam to blanket the turbine during periods of non-electric generation. }
\end{array} \\
& Q_{B O P, G A S} \text { is the fossil fuel used by the plant for non-thermal purposes. The use of natural } \\
& \text { gas to provide and inert gas blanket in the thermal storage system to keep oxygen } \\
& \text { out is an example at SEGS I. }
\end{aligned}
$$

Fossil fuel usage can be reported in volumetric basis or based on the lower heat value (LHV) of the fuel. If the fuel is reported on a volumetric basis, the LHV of the fuel must be reported as well. 


\section{Electric Generation and Consumption}

Gross Electric Generation: At most conventional power plants it is generally possible to measure the electricity produced by the turbine/generator. This is referred to as the gross electric generation ( $E_{T O T, G R}$ ). The gross electric generation is the power generated prior to any parasitic electric loads being subtracted off.

Since all existing trough plants are hybrid solar/fossil plants, it is desirable to break down the gross electric generation into its solar $\left(E_{S O L, G R}\right)$ and fossil $\left(E_{F O S, G R}\right)$ components. This allows the performance of each mode to evaluated separately, although, it is important to note that the hybrid portion of the plant generally influences solar plant performance.

$$
E_{\text {TOT }, G R}=E_{S O L, G R}+E_{F O S, G R}
$$

Depending of the type of hybridization, there are two methods generally used to split gross electric generation into solar and fossil components. The first method is used when the solar thermal $\left(Q_{\text {sol }}\right)$ and fossil thermal $\left(Q_{\text {FOS }}\right)$ input to the power turbine are converted at the same efficiency or when it is not possible to look at a separate conversion efficiency each of the sources. This method simply weights the electric generation by the ratio of the thermal energy input to the turbine. For example:

$$
E_{S O L, G R}=E_{\text {TOT }, G R} \cdot\left(\frac{Q_{S O L}}{Q_{S O L}+Q_{\text {FOS }}}\right)
$$

This approach is used at SEGS VIII \& IX where the backup fossil fired oil heaters are used to heat the HTF to the same temperature as the solar field. This approach is also used at SEGS I where a fossil fired independent superheater is used to superheat the solar generated steam. In this case it is not possible to look as separate efficiencies for each input source since the plant cannot operate on saturated steam.

The second method for splitting the gross electric generation into solar and fossil components is used when the solar and fossil thermal energy delivered to the power turbine is converted at different efficiencies. This method uses a ratio of thermal energies multiplied by their corresponding conversion efficiencies.

$$
E_{S O L, G R}=E_{T O T, G R} \cdot\left(\frac{Q_{S O L} \cdot \eta_{S O L}\left(P_{t o t}\right)}{Q_{S O L} \cdot \eta_{S O L}\left(P_{t o t}\right)+Q_{F O S} \cdot \eta_{F O S}\left(P_{t o t}\right)}\right)
$$

Where

$$
\begin{array}{ll}
P_{\text {tot }} & \begin{array}{l}
\text { is the average total gross electric power output of the power turbine during the } \\
\text { hybrid operation }
\end{array} \\
\eta_{S o L}\left(P_{\text {tot }}\right) & \begin{array}{l}
\text { is the efficiency of power turbine at converting the solar thermal energy to } \\
\text { electricity at the total gross electric output of the power turbine }
\end{array} \\
\eta_{F O S}\left(P_{\text {tot }}\right) \quad \begin{array}{l}
\text { is the efficiency of power turbine at converting the fossil thermal energy to } \\
\text { electricity at the total gross electric output of the power turbine. }
\end{array}
\end{array}
$$

This approach is used at SEGS II-VII were the steam working fluid from each source enters the power turbine at different process conditions or is mixed and the overall turbine efficiency and output is a result of the proportions from each source. Detailed turbine models may be necessary to determine the appropriate conversion efficiency to be used for each source. A simplifying assumption used at the SEGS plants, is to assume that the effective conversion efficiency of each thermal input stream is calculated as if the turbine 
were operated at the combined load from just that source. This approach provides a reasonable approximation of hybrid operation efficiencies based on actual operating experience at the SEGS plants. Note that the split into solar and fossil generation must be performed on an instantaneous or daily basis. It cannot be performed on an annual basis. Also note that equation 9 simplifies to equation 8 if the efficiency of the solar and fossil modes are the same.

Parasitic Electric Consumption: Parasitic electric consumption, sometimes referred to as station or hotel load, refers to the power used by the plant itself. This includes the power to operate the solar field, pumps, compressors, cooling tower fans, control systems, lighting, air conditioning units, and other electric powered plant equipment. It is generally important to identify whether the parasitic loads are supplied by on-site or internal generation $\left(E_{\mathbb{N N T}, P A R}\right)$, or whether they have to be supplied by power purchased from the utility or external generation ( $\mathrm{E}_{\mathrm{EXT}, \mathrm{PAR}}$ ). At many power plants, the price of power purchased is different than the price received for power sold to the utility.

$$
E_{\text {TOT }, P A R}=E_{I N T, P A R}+E_{\text {EXT }, P A R}
$$

For hybrid systems it is also desirable to identify whether the parasitic electric loads are attributed to solar generation $\left(E_{S O L, P A R}\right)$ or fossil generation $\left(E_{F O S, P A R}\right)$.

$$
E_{T O T, P A R}=E_{S O L, P A R}+E_{F O S, P A R}
$$

For many of the parasitic loads it is straight forward to identify whether the load is solar or fossil (e.g. power for solar field heat transfer fluid pumps, collectors, or the forced draft fans on the natural gas fired heaters and boilers). Other loads such as the off-line or night-time parasitic loads for the balance of plant can be more difficult to assign. For purposes of reporting, it is important that a consistent approach be used for allocating parasitic loads. For plants such as the SEGS plants that function primarily as a solar plant and use fossil energy as a backup, all off-line parasitic loads are assumed to be included as solar parasitics. Other plant designs which are primarily a fossil plant with solar boosting, such as the ISCCS, would include only the solar related off-line parasitic loads in the solar parasitic loads.

In many cases, plants may not have sufficient electric metering to easily split the parasitic loads into solar and fossil components. The approach used at the SEGS plants is to calculate the average parasitic load factor for boiler operation ( $F_{F O S \text { PAR }}$ ) during all days when the plant is operated with only the fossil boiler.

$$
\widetilde{J}_{F O S, P A R}=\frac{\sum_{\text {BlrOniy }} E_{I N T, P A R}}{\sum_{\text {BlrOnly }} E_{F O S, G R}}
$$

This approach can attribute some solar parasitics loads to boiler operation if the solar field is being operated during boiler operation. Typically these loads will be small compared with the parasitic load for operating the boiler and power plant. However, care should be taken to verify this conclusion, and adjustments should be made to $E_{\mathbb{I N T}, \text { PAR }}$ in equation 12 if this is not the case. Once $F_{\text {FOS,PAR }}$ has been determined, then the boiler parasitic load for the plant can be calculated using:

$$
E_{F O S, P A R}=E_{F O S, G R} \cdot \widetilde{J}_{F O S, P A R}
$$

The solar parasitic load is then calculated from equation 11. The net electric generation from solar and gas can be calculated.

$$
\begin{aligned}
& E_{S O L, N E T}=E_{S O L, G R}-E_{S O L, P A R} \\
& E_{F O S, N E T}=E_{F O S, G R}-E_{F O S, P A R}
\end{aligned}
$$




$$
E_{T O T, N E T}=E_{S O L, N E T}+E_{F O S, N E T}
$$

\section{Plant Capacity Factors and Solar Fraction}

Plant Capacity Factors: Capacity factor is a utility measure of how much a plant actually produces over a given period of time as compared with how much it would have produced if it had been operated at its rated output during the entire period. Capacity factors can be calculated for any time period of interest (e.g. daily, monthly, or annual). The annual plant capacity factor is calculated as follows:

$$
C F_{\text {Annual }}=\frac{E_{\text {ToT, NET }}}{P_{\text {Rated }} \cdot 8760}
$$

Where:

$$
\begin{aligned}
& P_{\text {rated }} \text { is the contractual net rated output of the plant } \\
& 8760 \text { is the number of hours in a year, } 8784 \text { hours is used for leap years. }
\end{aligned}
$$

For comparison of plants and technologies we are generally interested in the annual solar capacity factor, so for a hybrid plants this can be calculated as follows:

$$
C F_{\text {soL, Annual }}=\frac{E_{\text {SOL, NET }}}{P_{\text {Rated }} \cdot 8760}
$$

In most cases power projects are designed to provide power to meet the particular load demands of the utility. For example, the SEGS projects were designed to maximize power generation during the Southern California Edison on-peak time of use period. The on-peak period corresponds to the time when the utility sees the highest demand for power. In southern California this occurs between 1200 hours and 1800 hours on weekdays during June through September. This period corresponds to summer time air conditioning loads. From a financial standpoint, it is crucial for the SEGS projects to maximize electric generation during this period. The on-peak capacity factor indicates how successful a project is at generating power during this important time period.

$$
C F_{\text {onpeak }}=\frac{E_{\text {onpeak, NET }}}{P_{\text {Rated }} \cdot T_{\text {onpeak }}}
$$

Where:

$$
\begin{aligned}
& E_{\text {Onpeak, NET }} \text { is the total net electric generation during the on-peak period. } \\
& T_{\text {Onpeak }} \text { is the number of hours during the on-peak period. }
\end{aligned}
$$

Note that $\mathrm{P}_{\text {rated }}$ can be a contractual plant rating that is typically less than the physical plant maximum output. In fact, many of the SEGS plants routinely generate on-peak capacity factors in excess of $100 \%$, year after year [3]. Reporting of on-peak or some other capacity factor can provide a means of judging how successful a project has been at meeting its contractual obligations.

Net Solar Electric Fraction: For hybrid plants it is useful to understand how much of the total net electric generation comes from solar input. Solar fractions can be calculated for any time interval, but the annual solar fraction provides a useful metric for comparative purposes.

$$
S F_{\text {Ammaal }}=\frac{E_{S O L, N E T}}{E_{T O T, N E T}}
$$




\section{Net System Efficiency}

The net system efficiency shows how well a plant can convert energy input to electric output. With hybrid plants it is generally more useful to look at the solar and fossil components separately. The net fossil system efficiencies is calculated:

$$
\eta_{F O S, N E T}=\left(\frac{E_{F O S, N E T}}{Q_{E L E C, G A S}}\right)
$$

The net solar efficiency is calculated:

$$
\eta_{S O L, N E T}=\frac{\text { Net Solar Electric Output }- \text { Solar Gas Parasitics }}{\text { Direct Normal Insolation } \cdot \text { Collection Area }}
$$

The solar gas parasitics term corrects for the auxiliary fossil fuel used by the solar plant which could have otherwise been used to generate electricity.

$$
\eta_{S O L, N E T}=\frac{E_{S O L, N E T}-Q_{A U X, G A S} \cdot \eta_{F O S, N E T}}{\bar{H}_{B N} \cdot 365 \cdot A_{\text {aperature }}}
$$

Where:

$$
\begin{array}{ll}
\bar{H}_{B N} & \text { is the annual average daily direct normal insolation, } \\
A_{\text {aperature }} & \text { is the aperture area of the collector field, defined as the reflective surface area } \\
\text { projected onto the plane of the aperture, without compensation for receiver or } \\
\text { support shadowing, }
\end{array}
$$

For plants that do not have parallel fossil electric generation capability, $\eta_{F O S, N E T \text { can }}$ be estimated assuming an $80 \%$ heater efficiency multiplied by the annual solar power turbine efficiency. 


\section{REFERENCES}

1. Kolb, G., "Evaluation of Power Production From the Solar Electric Generating Systems at Kramer Junction: 1988-1993", Volume 1: Proceedings of the 1995 ASME/JSME/JSES International Solar Energy Conference, Maui, Hawaii, March 19-24, 1995.

2. Stine, W., and M. Powell, "Proposed Guidelines for Reporting Performance of a Solar Dish/Stirling Electric Generation System," Vol. 2: Proceedings of 28 $8^{\text {th }}$ IECEC, Atlanta, Georgia, 1993.

3. Cohen, G., D. Kearney, R. Cable, "Recent Improvements and Performance Experience at the Kramer Junction SEGS Plants", Proceedings of the 1996 ASME International Solar Energy Conference, San Antonio, Texas, March 31-April 3, 1996

4. Cohen,, G., H. Price, R. Cable, V. Dudley, R. Mahoney, "Efficiency Testing of SEGS Parabolic Trough Collector," Solar 93, Proceeding of the 1993 Annual Conference of the American Solar Energy Society, Washington, D.C., April 25-28, 1993.

5. Dudley, V., G. Kolb, M. Sloan, D. Kearney, Test Results: SEGS LS-2 Solar Collector, Sandia National Laboratories, SAND94-1884,Albuquerque, NM, December, 1994

6. Flachglas Solartechnik $\mathrm{GmbH}$, Assessment of Solar Thermal Trough Power Plant Technology and its Transferability to the Mediterranean Region - Final Report, Prepared for Grupo ENDESA, Cologne, Germany, June, 1994.

7. Price, H., P. Svoboda, D. Kearney, "Validation of the FLAGSOL Parabolic Trough Solar Power Plant Performance Model", Volume 1: Proceedings of the 1995 ASME/JSME/JSES International Solar Energy Conference, Maui, Hawaii, March 19-24, 1995.

8. North American Electric Reliability Council, Data Reporting Instructions for Generating Availability Data System, Princeton, New Jèrsey, October, 1989. 